\title{
The psychometric properties of the Compassionate Love Scale and the validation of the English and German 7-item Compassion for Others Scale (COS-7)
}

Marco Schlosser ${ }^{1 \star}$, Natalie G. Pfaff ${ }^{2 \star}$, Stefan R. Schweinberger ${ }^{23}$, Natalie L. Marchant ${ }^{1}$, Olga M. Klimecki $^{3.4}$

' Division of Psychiatry, Faculty of Brain Sciences, University College London, London, United Kingdom

2 Department of General Psychology, Institute of Psychology, Friedrich-Schiller-University of Jena, Jena, Germany

${ }^{3}$ Swiss Centre for Affective Sciences, University of Geneva, Geneva, Switzerland

${ }^{4}$ Department of Medicine and Department of Political Sciences, University of Geneva, Geneva, Switzerland

"These authors contributed equally.

Corresponding Author:

Marco Schlosser

UCL Division of Psychiatry, 6th Floor, Wings B, Maple House, 149 Tottenham Court Road, London W1T 7NF, United Kingdom

Email address: marco.schlosser@ucl.ac.uk 


\section{Abstract}

Background. An increasing body of scientific research on the nature, correlates, and effects of compassion has accrued over recent years. Expert agreement has not yet been reached on the conceptualisation of compassion for others, and existing self-report measures of compassion for others have often lacked psychometric quality and content validity. Recent publications of longer compassion measures represent significant strides towards ameliorating these issues. However, there is a need for psychometrically sound short scales for measuring compassion in timeconstrained research settings. To meet this need, one can assess the psychometric qualities of existing scales in order to develop robust short adaptations of such scales.

Methods. Study $1(N=501)$ empirically assessed the psychometric properties of the widely cited Compassionate Love Scale (CLS) to validate a new short scale of compassion for others (strangers) comprised of items from the CLS - the 7-item Compassion for Others Scale (COS-7). Study $2(N=332)$ addressed the absence of a German measure of compassion for others by validating a German version of the COS-7.

Results. The CLS did not display adequate model fit. Both the English and German versions of the COS-7 demonstrated adequate model fit, factor loadings, internal consistency, interpretability, convergent/divergent validity, and no floor/ceiling effects. Findings provide support for the English and German versions of the COS-7 as adequate short scales for measuring compassion for others. The German COS-7 is the first German measure of compassion for others published to date. 


\section{Introduction}

Compassion is a core element of many contemplative traditions and a wide range of professions spanning the domains of education, justice, and health care (Dahlsgaard, Peterson, \& Seligman, 2005; Ricard, 2015). Compassion is a complex construct uniting caring motivations, social intelligences, and context-dependent emotional textures that can be in reference to oneself and others (Gilbert, 2019; Khoury, 2019). Over recent years, compassion has become a major focus of empirical inquiry and vivid conceptual debates in research on prosocial behaviour (e.g., Klimecki, 2019; Seppälä et al., 2017). In general, compassion is understood as a response to suffering, which entails the desire to alleviate suffering (Goetz, Keltner, \& Simon-Thomas, 2010). Many dictionary definitions of compassion abound, yet there is a lack of consensus on the core characteristics defining compassion and the relationship of compassion with related constructs such as empathy, which denotes the sharing of feelings. For example, some researchers conceptualise compassion as a form of empathy (e.g., Klimecki \& Singer, 2013).

Others suggest that empathy can be viewed as a domain of compassion (see Strauss et al., 2016) and that affective states are not a necessary condition for compassion (e.g., Gilbert, 2019). Neuroscientific evidence indicates that compassion and empathy are associated with activations in different brain regions (Klimecki, Leiberg, Ricard, \& Singer, 2014).

Compassion for others has been related to higher levels of happiness and well-being, and lower levels of depressive symptoms and some forms of burnout (Gu, Baer, Cavanagh, Kuyken, \& Strauss, 2019; Mongrain, Chin, \& Shapira, 2011). However, some research has found inconsistent associations between compassion and other psychological constructs. For instance, several studies found no association between compassion for others and self-compassion, wellbeing (Durkin, Beaumont, Hollins Martin, \& Carson, 2016), or depressive symptoms (López, Sanderman, Ranchor, \& Schroevers, 2018). A variety of compassion-based interventions have been developed and preliminary evidence supports their ability to promote compassion and to positively affect a range of mental health-related outcomes (Gilbert, 2009; see Kirby, Tellegen, $\&$ Steindl, 2017). These promising findings, however, should be evaluated in the context of ongoing debates around the conceptualisations and measurement of compassion. These caveats are not unlike those encountered in concurrent debates surrounding psychological constructs that are equally difficult to define, operationalise, and capture (e.g., mindfulness; see Van Dam et al., 2018). 
Recent efforts have been made to dispel the conceptual mist surrounding the construct of compassion by delineating affective, behavioural, and cognitive aspects that could allow it to be theoretically and statistically distinguished from closely related constructs such as empathy, sympathy, altruism, and kindness. For instance, a recent review has consolidated a variety of existing psychological and Buddhist definitions and identified the following five domains of compassion: (I) recognising suffering, (II) understanding the universality of suffering, (III) feeling concern and empathy for the individual who is suffering, (IV) tolerating the personal distress caused by another's suffering, and (V) being motivated to act to alleviate suffering (Strauss et al., 2016). Informed by previous work using this five-element definitional framework (Gu, Cavanagh, Baer, \& Strauss, 2017), Gu et al. (2019) developed two new 20-item self-report scales capturing compassion for others and for self, respectively (Sussex-Oxford Compassion Scales; Gu, Baer, Cavanagh, Kuyken, \& Strauss, 2019). Another recent study developed and validated the 16-item Compassion Scale (Pommier, Neff, \& Tóth-Király, 2020) using the pool of 24 compassion items originally developed by Pommier (2010). This measure of compassion for others was derived from Neff's theoretical framework for self-compassion, which comprises the dimensions of emotional response, cognitive understanding, and paying attention to personal suffering (Neff, 2003). The development of these compassion scales presents a promising step toward establishing a pool of gold standard instruments that researchers can draw from. Importantly, however, there is still a need for shorter measures of compassion for others, which could be used in time-sensitive research settings. To meet this need, the present investigation assessed the psychometric properties of one of the most highly cited self-report measure of compassion, namely the 21-item Compassionate Love Scale (CLS; Sprecher \& Fehr, 2005), to validate a psychometrically robust short scale of compassion for others derived from the item pool of the CLS.

The CLS is a 21-item measure with two scale versions intended to capture levels of compassion (i) towards close others or (ii) towards strangers and humanity, respectively. The original item generation of the CLS was theoretically informed by previous work on love and spiritual experiences (Hendrick \& Hendrick,1986; Post, Underwood, Schloss, \& Hurlbut, 2002; Underwood, 2002) as well as prototype perspectives on love (Fehr \& Russell, 1991). As part of a review of the content validity and psychometric quality of all published self-report measures of compassion (Strauss et al., 2016), the CLS was rated to have only partially adequate content 
validity and partially satisfactory reliability and convergent validity. In a related study, expert groups reviewed the face validity of the 21 CLS items and concluded that four items should be removed as they were inadequate indicators of compassion (Gu et al., 2017). Further, three scale items use the word 'compassion' or 'compassionate'. By only using the word 'compassion' without combining it with other psycho-affective terms to capture the latent construct of compassion, one unwarrantedly assumes that individuals understand and define compassion uniformly. A shortened 5-item version of the CLS (Santa Clara CLS; Hwang, Plante, \& Lackey, 2008), which was developed to measure compassion towards strangers and humanity only, includes three of these conceptually problematic items. Psychometrically, the CLS development and validation study did not propose an a priori factor structure, conduct a confirmatory factor analysis, report factor loadings, or assess or report model fit indices. In the light of its prominent role in shaping the body of compassion research to date, it is important to conduct further psychometric assessment of the CLS.

Since the publication of the CLS (Sprecher \& Fehr, 2005), researchers have witnessed substantial advances in structural equation modelling approaches including factor analysis (Kline, 2015), an increased availability and accessibility of sophisticated statistical software, and a higher uptake of these methods and tools by researchers. It is particularly important to highlight that the assessment of the factor structure and the associated model fit - commonly based on confirmatory factor analysis or related approaches (e.g., exploratory structural equation modelling) - has become a requirement in best practice guidelines for scale development and validation procedures (Kline, 2015). Without an adequate model fit of the hypothesised factor structure, the interpretation of any estimates derived from the model as well as the correlational or causal association of the scale scores with other measures is unwarranted. To date, no confirmatory factor analysis assessing the model fit of the CLS has been published.

To properly contextualise the present studies, two important points bear repeating: first, there is evidence that the CLS - one of the most frequently employed self-report measures in compassion research - has limitations when it comes to measuring compassion for others (strangers); and second, compassion research - as any established research field - requires a wide pool of psychometrically robust measures including shorter measures applicable to use in time-constrained research settings. Furthermore, no validated German measure of compassion for others has been published to date. 


\section{Study 1}

The purpose of Study 1 was to (1) assess the psychometric properties of the CLS for others (strangers) in a large, international community sample; and to (2) validate a short, psychometrically robust measure of compassion for others comprised of select items from the CLS.

\section{Materials \& Methods \\ Procedures}

This study collected cross-sectional data using an anonymous online survey. The online platform Prolific (see Palan \& Schitter, 2018) was used to recruit participants. Individuals were informed that the survey intended to further the scientific understanding of the relationship between compassion, subjective experiences, and social behaviour. A minimum age of 18 years and a good understanding of the English language were the inclusion criteria. Before starting the survey, individuals were asked to indicate whether they have read and understood the explanations and to voluntarily indicate written consent to participate in this study. The survey took approximately 8 minutes to complete and participants were reimbursed with $£ 0.90$. All data were collected between in June 2019. The study and consent procedures of Study 1 were approved by University College London's research ethics committee (ref no: 10043/002) and performed in line with the Declaration of Helsinki.

Prolific verifies and monitors participants and data quality with extensive checks (see Peer, Brandimarte, Samat, \& Acquisti, 2017). We assessed the standard deviation of each participant's item responses on a given survey page. Each of the four self-report measures was displayed on a separate survey page. We detected no participants who consistently indicated the same response for each item (i.e., $\mathrm{SD}=0$ ) on more than two measures (i.e., $50 \%$ of survey). We followed Jackson's (2001) recommendation to recruit at least 200 participants for confirmatory factor analysis with maximum likelihood estimation. A total of 516 individuals from the general population started the survey. Fifteen participants did not complete the CLS and were excluded. Thus, data from 501 participants were included in the analyses. Most participants $(n=384)$ were asked to provide demographic details and complete measures of compassion, prosocialness, empathy, and social value orientation. Inter-correlations of these measures were computed using data from these participants. The remaining participants $(n=117)$ were asked to only complete demographic items and the CLS. 


\section{Participants}

The total sample of 501 participants (269 female) had a mean age of 29.8 years $(\mathrm{SD}=$ 10.2, range 18 to 72 ). Participants had, on average, completed 15.5 years ( $\mathrm{SD}=3.2$ ) of education and more than two-thirds of participants had attended university $(71.7 \%)$. The distribution of country of residence was 40\% United Kingdom, 13\% Portugal, 8\% Poland, 6\% United States, 4\% Australia and New Zealand, 2\% Canada, 26\% other European countries, and 1\% Asian countries.

\section{Measures}

Compassion. Compassion was measured using the Compassionate Love Scale (strangerhumanity version; Sprecher \& Fehr, 2005). The CLS is a 21-item measure that uses a 7-point Likert scale ranging from 1 (not at all true of me) to 7 (very true of me). Total CLS scores are derived by averaging all item scores. The CLS has no subscales. Higher CLS total scores indicate higher levels of compassion. The CLS has displayed good internal consistency with a Cronbach's alpha of 0.95 (Sprecher \& Fehr, 2005).

Prosocialness. Prosocialness was measured using the Prosociality Scale (Caprara, Steca, Zelli, \& Capanna, 2005). The Prosociality Scale is a 16-item questionnaire with a 5-point Likert scale ranging from 1 (never/ almost never true) to 5 (almost always/ always true) that captures how much individuals engage in sharing, helping, and empathising with others. Total scores are computed by averaging all item scores, with higher scores indicating higher levels of prosocialness. The Prosociality Scale has displayed good internal consistency (Cronbach's alpha of 0.91; Caprara et al., 2005).

Empathy. Empathic tendencies were measured using the Interpersonal Reactivity Index (IRI; Davis, 1983). The IRI is a 28-item measure with four 7-item subscales that use a 5-item scale ranging from $\mathrm{A}$ (Does not describe me well) to $\mathrm{E}$ (Describes me very well) to capture four distinct aspects of empathy: empathic concern (other-oriented feelings of sympathy and concern), perspective taking (ability to spontaneously adopt another's psychological view), fantasy (tendency to transpose oneself into the psychological experience of fictitious characters in books, movies, etc.), and personal distress (self-oriented feelings of unease in interpersonal dynamics). Letters A to E were converted to numbers 0 to 4 . The total subscale scores are computed by summing the respective item scores (after reverse-scoring some items). The IRI has displayed satisfactory internal consistency with a Cronbach's alpha of $0.80,0.79,0.82$, and 0.75 
for empathic concern, perspective taking, fantasy, and personal distress, respectively (Davis, 1983).

Social Value Orientation. The level of concern an individual has for others was measured using the Social Value Orientation Slider Measure (SVO; Murphy, Ackerman, \& Handgraaf, 2011). The six primary SVO items, each with nine response options, were used in the present study. For each item, participants were asked to distribute money between themselves and one other person, who they remained anonymous to. Each of the nine response options per item described a different allocation distribution participants could choose from (e.g., "You receive \$50. Other receives \$40.”). A single total score was computed (described in detail in Murphy, Ackerman, \& Handgraaf, 2011) with higher scores indicating higher levels of concern for others. The SVO has displayed excellent psychometric properties (e.g., test-retest reliability = 0.92; Murphy, Ackerman, \& Handgraaf, 2011).

\section{Analytic Approach}

First, confirmatory factor analysis with maximum likelihood estimation was used to assess the model fit of a one-factor solution for the CLS. The following model fit indices were judged to be most informative in the context of the present study: the comparative fit index (CFI), the Tucker-Lewis Index (TLI), the root mean square error of approximation (RMSEA), and the standardised root mean square residual (SRMR). CFI and TLI values above 0.95 and SRMR values below 0.8 are commonly interpreted to indicate excellent model fit (Hu \& Bentler, 1999). RMSEA values below 0.08 suggest an acceptable fit (Browne \& Cudeck, 1992). Results of the more traditional chi-square test were also reported; however, the chi-square test statistic can be considered unreliable in the context of larger sample sizes (Byrne, 2001). The fit indices of the one-factor model of the CLS or the raw data from the original CLS validation paper (Sprecher \& Fehr, 2005) were requested from the authors; however, this information was, unfortunately, not available.

Second, we aimed to use items from the 21-item pool of the CLS to create a new compassion scale with optimized psychometric properties. Any items that were judged by experts to display poor or ambiguous content validity were removed. Based on previous research (Gu et al., 2017; Strauss et al., 2016), we a priori removed four items (7, 11, 13, 20) because they inadequately capture compassion and three additional items $(3,6,9)$ because they assume that participants know and (uniformly) define the construct of compassion or compassionate 
love. The remaining 14 items from the CLS were then independently evaluated by two authors (MS and $\mathrm{OK}$ ) for their content validity and classified as either adequate or inadequate. All inadequate items were removed. The remaining items were combined into a new compassion scale and included in a one-factor confirmatory factor analysis in which all items directly loaded on a single compassion factor.

The one-factor model was evaluated using model fit, factor loadings, and commonality. Reliability of the scale was assessed with internal consistency and item-test correlation estimates and alpha-if-item-deleted values. Distribution and floor and ceiling effects of the total scores were tested by assessing the histogram of the total scores, skewness and kurtosis estimates, and the percentage of participants scoring the minimum and maximum total score. Published criteria suggest that, overall, less than $15 \%$ of participants should report the lowest or highest total score (Terwee et al., 2007). Interpretability was tested by comparing total compassion scores based on sex and education. In line with previous research (e.g., Gu et al., 2019; Pommier, Neff, \& TóthKirály, 2020), female participants were predicted to report higher levels of compassion than male participants; no differences in relation to education were expected. Convergent validity was assessed by Pearson's correlation coefficients of this adapted compassion scale with the selfreport measures listed above. Specifically, total scores of our compassion scale were expected to display substantial correlations with empathic concern, perspective taking, and prosocialness $(r \geq$ $0.5)$ and moderate correlations with social value orientation $(0.3 \leq r<0.5)$. We predicted weaker correlations with personal distress and fantasy, which are facets of empathy and as such related to compassion $(r<0.30)$. We judged correlations at $r>0.80$ to indicate that measures might capture the same latent construct (i.e., display conceptual redundancy). We thus expected our adapted compassion scale to highly correlate with the CLS. All analyses were conducted in Stata version 13.

\section{Data Availability}

All data and analysis scripts of Study 1 are available at the Open Science Framework (https://osf.io/yrq4j/).

\section{Results}

\section{Compassionate Love Scale (CLS)}


Confirmatory factor analysis. Confirmatory factor analysis indicated that the one-factor model of the CLS did not have an adequate model fit, indicating that the latent construct of compassion is not meaningfully captured (Table 1).

\section{7-item Compassion for Others Scale (COS-7)}

Item assessment. From the $14 \mathrm{CLS}$ items that remained after a priori removing problematic items, a further six items were removed because they did not clearly relate to the suffering of an individual $(4,14,16,18,19,21)$, and one item because it displayed a large conceptual overlap with items from established empathy scales (17). Thus, a total of seven items were removed, leaving seven items to form a compassion scale with adequate face validity. Table 2 displays an overview of reasons for item exclusion.

Confirmatory factor analysis. Seven items were included in a one-factor confirmatory factor analysis. Three fit indices indicated an excellent fit (CFI = 0.974; TLI = 0.961; SRMR = 0.028 ) and one indicated an acceptable fit (RMSEA $=0.079,90 \%$ CI: 0.058 to 0.101$)$ of the 7 item compassion scale (from here on referred to as the 7-item Compassion for Others Scale [COS-7]). Standardised factor loadings ranged in magnitude from 0.62 to 0.86 (all associated with $p<0.001$; mean $=0.72$ ). Commonality estimates (all $\geq 0.4$ ) indicated that an adequate proportion of the variance of each item was accounted for by the compassion factor.

Reliability. The COS-7 scale displayed good internal consistency with a Cronbach's alpha of 0.89 . Item-test correlation estimates were $\geq 0.70$ and alpha-if-item-deleted values were $>0.85$. All estimates are reported in Table 3 .

Floor and ceiling effects. In the present sample, COS-7 total scores had a mean of 4.20 $(\mathrm{SD}=1.20)$ and a range of 1 to 7 . The distributions of COS-7 total scores did not substantially diverge from normality as indicated by estimates of skewness (-0.29) and kurtosis (2.63) and visual inspection of the histogram. Only $0.2 \%$ of participants had the highest possible COS-7 total score and $0.5 \%$ of participants had the lowest possible COS-7 total score. Thus, the COS-7 total scores captured a wide range of levels of compassion and did not show floor or ceiling effects (Table 4).

Interpretability. Results from two simple linear regression models that used COS-7 total scores as continuous outcome variable and sex and university attendance as binary explanatory variable, respectively, indicated that female participants reported higher COS-7 scores than male participants (unstandardised mean difference $=0.32 ; 95 \%$ CI: 0.11 to $0.53 ; p=0.003$ ) but that 
participants who had attended university did not differ in COS-7 scores from those who had not (unstandardised mean difference $=-0.02 ; 95 \% \mathrm{CI}:-0.25$ to $0.22 ; p=0.894$ ).

Convergent and discriminant validity. Pearson's correlation coefficients between the scores of the COS-7 and scores of measures of empathy, prosocialness, and social value orientation are displayed in Table 4. COS-7 were highly correlated with prosocialness $(r=0.73$, $p<0.001)$ and empathic concern $(r=0.65, p<0.001)$ and moderately correlated with

perspective taking $(r=0.38, p<0.001)$ and social value orientation $(r=0.26, p<0.001)$. COS-7 scores were weakly correlated with fantasy $(r=0.20, p<0.001)$ and personal distress $(r=0.14$, $p=0.007)$. In sum, two correlations of the COS-7 with related measures were $r \geq 0.5$ and none were $r>0.8$, thus indicating adequate convergent and discriminant validity. As expected, the COS-7 and CLS were highly correlated $(r=0.96, p<0.001)$.

In sum, these findings suggest that the COS-7 is a psychometrically robust measure of compassion.

\section{Study 2}

The primary purpose of Study 2 was to assess the psychometric properties of the German version of the CLS and to validate a German version of the COS-7 and thereby introduce the first validated measure of compassion for others in German.

\section{Materials \& Methods}

\section{German Adaptation of the Scale}

The 21 items of the English CLS were independently translated into German by two bilingual experts in psychology and research on compassion. A third bilingual expert judged the precision of both translations and harmonised them into an additional translation. A fourth bilingual expert back-translated this third German version into English and compared it with the original English version of the CLS. A fifth bilingual expert oversaw and judged the validity of the entire translation process, while consulting a German translation of the CLS that is used in the European Commission-funded H2020 Silver Santé Study (Lutz et al., 2018; Marchant et al., 2018; Poisnel et al., 2018). A German version of the COS-7 is provided in Table 5. The German translation of the CLS is provided in Table S1 (Supplemental File).

\section{Procedures}

The procedures of Study 2 followed those of Study 1: Cross-sectional data was collected via an anonymous online survey. Participants were recruited via Prolific (see Palan \& Schitter, 
2018). Individuals were informed that this study aimed to improve the scientific understanding of the relationship between compassion, subjective experiences, and social behaviour. A good understanding of the German language and a minimum age of 18 years were the inclusion criteria. Before starting the survey, individuals had to indicate whether they have read and understood the explanations and to voluntarily indicate written consent to participate. The survey took approximately 6 minutes to complete and participants were reimbursed with $£ 0.80$. All data were collected in September 2019. The study and consent procedures of Study 2 were approved by University College London's research ethics committee (ref no: 10043/002) and performed in line with the Declaration of Helsinki.

A total of 361 individuals started the survey. Eleven participants did not complete the CLS and were excluded. A further 18 participants were excluded because they failed an attention check question ("Es ist wichtig, dass Sie diesen Fragebogen mit voller Aufmerksamkeit beantworten. Bitte wählen Sie: Beschreibt mich sehr gut." [English: "It is important that you answer this survey with full attention. Please indicate: Describes me well."]). Thus, data from 332 participants were included in the analyses.

\section{Participants}

The total German sample of 332 participants (163 female) had a mean age of 30.1 years $(\mathrm{SD}=9.7$, range 18 to 67$)$. Participants had, on average, completed 16.0 years $(\mathrm{SD}=3.6)$ of education and $74.1 \%$ of participants had attended university. All participants indicated German as their first language. A total of $12.4 \%$ of participants indicated that they meditate regularly and had, on average, maintained a regular practice for 3.1 years $(\mathrm{SD}=5.1)$, ranging from 1 month to 25 years.

\section{Measures}

Compassion. Participants completed the German translation of the English CLS (Sprecher \& Fehr, 2005), which includes all items from the COS-7 that was validated in Study 1. The CLS and COS-7 use a 7-point Likert scale ranging from 1 (not at all true of me) to 7 (very true of me) to capture levels of compassion. Total scores are derived by averaging all item scores. Higher total scores indicate higher levels of compassion for others (strangers).

Prosocial tendencies. To measure prosocial tendencies, we used the German version of the Revised Prosocial Tendencies Measure (Rodrigues, Ulrich, Mussel, Carlo, \& Hewig, 2017). The Revised Prosocial Tendencies Measure is a 23-item questionnaire with a 5-point Likert scale 
ranging from 1 (does not describe me at all) to 5 (describes me very well). Six subscales capture six domains of prosocial behaviour: altruistic, anonymous, public, emotional, dire, and compliant prosocial behaviour. Subscale total scores are computed by averaging their respective item scores, with higher scores indicating higher levels of the respective construct. The altruistic subscale items must be reverse-scored before computing the altruistic subscale total score. The Revised Prosocial Tendencies Measure has displayed good psychometric properties (Rodrigues et al., 2017).

Empathy. To measure empathic tendencies, we used the German version of the Interpersonal Reactivity Index (SPF-IRI; Paulus, 2009). In contrast to the original IRI (Davis, 1983) described in Study 1, the German IRI includes only 16 items, none of which are reverse scored. The German IRI has displayed satisfactory internal consistency with a Cronbach's alpha of $0.71,0.71,0.74$, and 0.66 for empathic concern, perspective taking, fantasy, and personal distress, respectively (Paulus, 2009).

Social value orientation. To measure the level of concern an individual has for others, we used the German version of the Social Value Orientation Slider Measure (SVO; Murphy, Ackerman, \& Handgraaf, 2011) described in Study 1.

\section{Analytic Approach}

Confirmatory factor analysis with maximum likelihood estimation was used to assess the model fit of a one-factor solution for the German CLS and German COS-7. The assessment of the model fit and reliability followed the factor analytic approach described in Study 1. Interpretability was tested by comparing COS-7 total scores based on sex, education, and meditation experience. Based on previous research (e.g., Gu et al., 2019; Pommier, Neff, \& Tóth-Király, 2020), we expected female participants and regular meditators to report higher COS-7 total scores.

\section{Data Availability}

All data and analysis scripts of Study 2 are available at the Open Science Framework (https://osf.io/yrq4j/).

\section{Results}

Confirmatory factor analysis. Confirmatory factor analysis indicated that the one-factor model of the German CLS did not have an adequate model fit, suggesting that the compassion factor is not meaningfully captured. The German COS-7 displayed a good model fit (Table 1). 
Reliability. The German COS-7 scale displayed good internal consistency with a Cronbach's alpha of 0.89 . Item-test correlation estimates were $\geq 0.68$ and alpha-if-item-deleted values were $\geq 0.86$. All estimates are reported in Table 5 .

Floor and ceiling effects. In the present sample, German COS-7 total scores had a mean of $4.20(\mathrm{SD}=1.21)$ and a range of 1 to 7 . The distributions of COS-7 total scores did not substantially diverge from normality as indicated by estimates of skewness $(-0.18)$ and kurtosis (2.41) and visual inspection of the histogram. Only $0.3 \%$ of participants had the highest possible COS-7 total score and $0.3 \%$ of participants had the lowest possible COS-7 total score. Thus, the German COS-7 total scores captured a wide range of levels of compassion and did not display floor or ceiling effects.

Interpretability. Results from three simple linear regression models that used German COS-7 total scores as continuous outcome variable and sex, meditation practice, and university attendance as binary explanatory variable, respectively, indicated that female participants reported higher COS-7 total scores than male participants (unstandardised mean difference $=$ $0.77 ; 95 \%$ CI: 0.53 to $1.01 ; p<0.001)$, that participants with a regular meditation practice reported higher COS-7 total scores (unstandardised mean difference $=0.70 ; 95 \%$ CI: 0.30 to $1.09 ; p=0.001$ ), and that participants who had attended university reported higher COS-7 total scores than those who had not (unstandardised mean difference $=0.34 ; 95 \%$ CI: 0.05 to $0.63 ; p=$ $0.021)$.

Convergent and discriminant validity. Pearson's correlation coefficients between the scores of the German COS-7 and scores of measures of prosocial tendencies, empathy, and social value orientation are displayed in Table 6. The German CLS and German COS-7 were highly correlated $(r=0.96, p<0.001)$.

Taken together, these findings suggest that the German COS-7 is a psychometrically sound measure of compassion.

\section{Discussion}

The present studies aimed to refine the measurement of compassion by building on the widely used CLS (Sprecher \& Fehr, 2005). Three key findings emerged. First, we offer psychometric evidence that the widely used CLS is a suboptimal measure of compassion for others (strangers). Second, altering this measure using a priori determined criteria provides a more psychometrically robust measure of compassion for others, the 7-item Compassion for 
Others Scale (COS-7). Third, we introduce a psychometrically robust German version of the COS-7, which is the first validated German measure of compassion for others published to date.

So far, the psychometric properties of the CLS have not been sufficiently tested or reported. For instance, no assessment of model fit of the proposed one-factor structure of the CLS has previously been published. Using a large international community sample, we show that the model fit indices of the widely used CLS are not satisfactory. These finding underscore the value of two recently developed longer measures of compassion for others that have displayed good psychometric properties, namely the Sussex-Oxford Compassion Scale-Other (Gu et al., 2019) and the Compassion Scale (Pommier, Neff, \& Tóth-Király, 2020).

In developing the English COS-7, the choice of scale items from the 21 -item pool of the CLS was guided by expert judgment and informed by previous research indicating that the CLS contains several items with inadequate content validity (Gu et al., 2017; Strauss et al., 2016). In our international sample, a model with seven indicators loading directly on one compassion factor was fit to the data. All items displayed very high factor loadings and model fit indices were acceptable to excellent. Further, the COS-7 displayed good internal consistency and adequate item-test correlation estimates. COS-7 total scores displayed no floor or ceiling effects. Consistent with previous research (Pommier, 2010; Pommier, Neff, \& Tóth-Király, 2020), female participants in the international sample had significantly higher COS-7 scores.

Our findings suggest that the English COS-7 also displayed adequate levels of convergent and discriminant validity. As predicted, the COS-7 was highly correlated with levels of empathic concern for others and prosocialness (i.e., the inclination to help and share with others), but not so highly correlated as to be indicative of conceptual redundancy. Slightly diverging from our predictions, the correlation between the COS-7 and perspective taking (i.e., the ability to adopt another's view) was only moderate in size. This finding, however, is partially echoed by recent research (Gu et al., 2019) - which was published after the collection of our data and thus did not inform our predictions - indicating a high correlation between perspective taking and compassion in a sample of health care staff but only a moderate correlation between these two measures in a student sample. There were weak associations of COS-7 scores with two other aspects of empathy: fantasy (i.e., the ability to imagine oneself having the experience of a protagonist in a book or film) and personal distress (i.e., the levels of personal anxiety and difficulty one experiences in tense interpersonal dynamics). This is in line with research that did 
not consider fantasy a core part of empathy (Neff \& Pommier, 2013) and research that found only a small correlation between distress and compassion for others (Pommier, 2010).

Given that the English COS-7 consists of items of the widely used CLS, it also allows researchers to re-analyse previously collected data using the current 7-item version. For instance, previous research with established compassion measures (see Strauss et al., 2016) did not find evidence for a relationship between compassion for others and measures of mental health and well-being (e.g., Durkin et al., 2016; López et al., 2018). Moreover, several theoretical frameworks conceptualise compassion for others and self-compassion as components of an overarching construct (e.g., Burbea, 2014; Feldman \& Kuyken, 2011), but empirical studies did not find a strong relationship between these forms of compassion (e.g., Gu et al., 2019; Pommier, Neff, \& Tóth-Király, 2020). Re-evaluating previous findings using the English COS-7 could increase the confidence in this nascent research field and present an important step towards ameliorating the measurement limitations and validity concerns currently affecting the empirical literature on compassion (Strauss et al., 2016).

For Study 2, we translated the items of the CLS into German. These items were then administered to a large community sample of participants who spoke German as their first language. A pattern of findings emerged that mirrored those found in Study 1: the German CLS lacked adequate model fit, whereas the German COS-7 displayed good psychometric properties including adequate levels of convergent and discriminant validity. The German COS-7 scores were most highly correlated with empathic concern, emotional prosocial behaviour (i.e., the tendency to help others under emotionally evocative circumstances) and dire prosocial behaviour (i.e., the tendency to help others in crisis situations). Public prosocial behaviour that captures the tendency to engage in altruistic behaviour to appear altruistic in public or to increase one's selfesteem were not related to German COS-7 scores. Further, there was no association between the German COS-7 and altruistic prosocial behaviour, which aims to measure voluntary helping behaviour driven by internalised altruistic principles and concerns for others. Future research including alternative German measures of altruism is needed to understand whether this absence of an association might be related to the characteristics of the altruism measure utilised in Study 2. More specifically, the items of the altruistic prosocial behaviour subscale (e.g., "Ich denke, eines der besten Dinge daran anderen zu helfen ist, dass es mich gut aussehen lässt." [Original English: "I think that one of the best things about helping others is that it makes me look good."']; 
Rodrigues et al., 2017) are reverse-scored and may capture the absence of self-interest more than the active presence of altruism.

Study 2 also collected information on meditation experience. Compassion for others and self-compassion have frequently been posited as theoretically consistent mechanisms of action underlying some of the effects of meditation on mental health - a hypothesis that has been corroborated by empirical evidence (e.g., Khoury, Knäuper, Schlosser, Carrière, \& Chiesa, 2017; Schlosser, Jones, Demnitz-King, \& Marchant, in press). As predicted based on previous crosssectional research (e.g., Gu et al., 2019; Pommier, Neff, \& Tóth-Király, 2020), regular meditators in our sample displayed significantly higher levels of compassion than meditationnaïve participants.

The German COS-7 is the first psychometrically validated German measure of compassion for others published to date and complements the German version of the SelfCompassion Scale (Coroiu et al., 2018).

\section{Limitations and Future Research}

Our findings should be interpreted in the context of several important limitations. Firstly, in both studies only one method of data collection was applied (i.e., online questionnaires). Secondly, the cross-sectional nature of our data did not allow us to assess other psychometric properties such as predictive validity and test-retest reliability. Future longitudinal studies including compassion-based interventions that administer the COS-7 at several time points are needed to examine these statistical properties as well as the sensitivity of the COS-7 to compassion training. Thirdly, although our sample size in Study 1 was much larger and more representative (i.e., not constrained to undergraduate students) than the samples utilised in the development and validation of the CLS (Sprecher \& Fehr, 2005), we only collected few variables to characterise our samples (i.e., age, sex, education, country of residence; plus meditation experience in Study 2) and thereby might have missed potentially important characteristics that could have influenced our findings (e.g., personality, medical history, profession). Relatedly, participants in both studies were highly educated. Future research is needed to assess if the present findings can be replicated in demographically more diverse samples. The present samples were recruited from non-clinical populations. Given that many compassion-based interventions are also tailored for participants with existing mental health problems, it is vital to examine the psychometric properties of the COS-7 in clinical and help-seeking samples. 


\section{Conclusions}

In sum, our findings help advance empirical research on compassion by introducing short and psychometrically validated scales to measure compassion for others (strangers) in English and German. Importantly, they address previous conceptual concerns and measurement limitations: they only include items with high content validity as judged by experts; their psychometric properties are adequate; and their brevity meets the need for adequate compassion measures suitable to research in time-constrained settings including large-scale trials and epidemiological cohort studies. Unrelated to its brevity, the German COS-7 presents the first German measure of compassion for others. Refining and expanding the range of compassion measures available to researchers remains an important task to support the progress and maturation of the research field. 


\section{References}

Browne, M., \& Cudeck, R. (1992).Alternative ways of assessing model fit. Sociol. Methods. Res., 21(2), 230-258.

Burbea, R. (2014). Seeing that frees: meditations on emptiness and dependent arising:

Troubador Publishing Ltd.

Byrne, B. M. (2001). Structural Equation Modeling: Perspectives on the Present and the Future. International Journal of Testing, 1(3-4), 327-334. doi:10.1080/15305058.2001.9669479

Caprara, G. V., Steca, P., Zelli, A., \& Capanna, C. (2005). A New Scale for Measuring Adults' Prosocialness. European Journal of Psychological Assessment, 21(2), 77-89. doi:10.1027/10155759.21.2.77

Coroiu, A., Kwakkenbos, L., Moran, C., Thombs, B., Albani, C., Bourkas, S., Zenger M., Brahler E., \& Koerner, A. (2018). Structural validation of the Self-Compassion Scale with a German general population sample. PloS one, 13(2). doi:10.1371/journal.pone.0190771

Dahlsgaard, K., Peterson, C., \& Seligman, M. E. P. (2005). Shared Virtue: The Convergence of Valued Human Strengths Across Culture and History. Review of General Psychology, 9(3), 203213. doi:10.1037/1089-2680.9.3.203

Davis, M. H. (1983). Measuring individual differences in empathy: Evidence for a multidimensional approach. Journal of Personality and Social Psychology, 44(1), 113-126. doi:10.1037/0022-3514.44.1.113

Durkin, M., Beaumont, E., Hollins Martin, C. J., \& Carson, J. (2016). A pilot study exploring the relationship between self-compassion, self-judgement, self-kindness, compassion, professional quality of life and wellbeing among UK community nurses. Nurse Education Today, 46, 109114. doi:10.1016/j.nedt.2016.08.030 
Fehr, B., \& Russell, J. A. (1991). The concept of love viewed from a prototype perspective. Journal of Personality and Social Psychology, 60(3), 425.

Feldman, C., \& Kuyken, W. (2011). Compassion in the landscape of suffering. Contemporary Buddhism, 12(1), 143-155. doi:10.1080/14639947.2011.564831

Gilbert, P. (2009). Introducing compassion-focused therapy. Advances in Psychiatric Treatment, 15(3), 199-208. doi:10.1192/apt.bp.107.005264

Gilbert, P. (2019). Explorations into the nature and function of compassion. Current Opinion in Psychology, 28. doi:10.1016/j.copsyc.2018.12.002

Goetz, J. L., Keltner, D., \& Simon-Thomas, E. (2010). Compassion: An Evolutionary Analysis and Empirical Review. Psychological Bulletin, 136(3), 351-374. doi:10.1037/a0018807

Gu, J., Baer, R., Cavanagh, K., Kuyken, W., \& Strauss, C. (2019). Development and psychometric properties of the Sussex-Oxford compassion scales (SOCS). Assessment, 27(1), 320. doi:10.1177/1073191119860911

Gu, J., Cavanagh, K., Baer, R., \& Strauss, C. (2017). An empirical examination of the factor structure of compassion. PLoS One, 12(2), e0172471. doi:10.1371/journal.pone.0172471

Hendrick, C., \& Hendrick, S. (1986). A theory and method of love. Journal of personality and social psychology, 50(2), 392.

Hu, L. T., \& Bentler, P. M. (1999). Cutoff criteria for fit indexes in covariance structure analysis: Conventional criteria versus new alternatives. Structural Equation Modeling: A Multidisciplinary Journal, 6(1), 1-55. doi:10.1080/10705519909540118 
Hwang, J., Plante, T., \& Lackey, K. (2008). The Development of the Santa Clara Brief Compassion Scale: An Abbreviation of Sprecher and Fehr's Compassionate Love Scale. Pastoral Psychology, 56(4), 421-428. doi:10.1007/s11089-008-0117-2

Jackson, D. L. (2001). Sample size and number of parameter estimates in maximum likelihood confirmatory factor analysis: A Monte Carlo investigation. Structural Equation Modeling, 8(2), 205-223. doi:10.1207/S15328007SEM0802_3

Khoury, B. (2019). Compassion: Embodied and Embedded. Mindfulness, 10(11), 2363-2374. doi:10.1007/s12671-019-01211-w

Khoury, B., Knäuper, B., Schlosser, M., Carrière, K., \& Chiesa, A. (2017). Effectiveness of traditional meditation retreats: A systematic review and meta-analysis. Journal of Psychosomatic Research, 92, 16-25. doi:10.1016/j.jpsychores.2016.11.006

Kirby, J. N., Tellegen, C. L., \& Steindl, S. R. (2017). A Meta-Analysis of Compassion-Based Interventions: Current State of Knowledge and Future Directions. Behavior Therapy, 48(6), 778792. doi:10.1016/j.beth.2017.06.003

Klimecki, O. M. (2019). The Role of Empathy and Compassion in Conflict Resolution. Emotion Review, 11(4), 310-325. doi:10.1177/1754073919838609

Klimecki, O., \& Singer, T. (2013). Empathy from the Perspective of Social Neuroscience. In: Armony, J. \& Vuilleumier, P. The Cambridge Handbook of Human Affective Neuroscience. New York: Cambridge University Press, 2013.

Klimecki, O. M., Leiberg, S., Ricard, M., \& Singer, T. (2014). Differential pattern of functional brain plasticity after compassion and empathy training. Social Cognitive and Affective Neuroscience, 9(6), 873-879. doi:10.1093/scan/nst060 
Kline, R. B. (2015). Principles and practice of structural equation modeling. Guilford publications.

López, A., Sanderman, R., Ranchor, A., \& Schroevers, M. (2018). Compassion for Others and Self-Compassion: Levels, Correlates, and Relationship with Psychological Well-being. Mindfulness, 9(1), 325-331. doi:10.1007/s12671-017-0777-z

Lutz, A., Klimecki, O. M., Collette, F., Poisnel, G., Arenaza-Urquijo, E., Marchant, N. L., et al. (2018). The Age-Well observational study on expert meditators in the Medit-Ageing European project. Alzheimer's \& Dementia: Translational Research \& Clinical Interventions, 4, 756-764. doi:10.1016/j.trci.2018.11.002

Marchant, N. L., Barnhofer, T., Klimecki, O. M., Poisnel, G., Lutz, A., Arenaza-Urquijo, E., et al. (2018). The SCD-Well randomized controlled trial: Effects of a mindfulness-based intervention versus health education on mental health in patients with subjective cognitive decline (SCD). Alzheimer's \& Dementia: Translational Research \& Clinical Interventions, 4(C), 737-745. doi:10.1016/j.trci.2018.10.010

Mongrain, M., Chin, J., \& Shapira, L. (2011). Practicing Compassion Increases Happiness and Self-Esteem. An Interdisciplinary Forum on Subjective Well-Being, 12(6), 963-981. doi:10.1007/s10902-010-9239-1

Murphy, R., Ackerman, K., \& Handgraaf, M. (2011). Measuring social value orientation. Judgment and Decision Making, 6(8), 771. doi:10.2139/ssrn.1804189

Neff, K. (2003). Self-compassion: An alternative conceptualization of a healthy attitude toward oneself. Self and identity, 2(2), 85-101. doi:10.1080/15298860309032

Neff, K. D., \& Pommier, E. (2013). The Relationship between Self-compassion and Otherfocused Concern among College Undergraduates, Community Adults, and Practicing Meditators. Self and Identity, 12(2), 160-176. doi:10.1080/15298868.2011.649546 
Palan, S., \& Schitter, C. (2018). Prolific. ac—A subject pool for online experiments. Journal of Behavioral and Experimental Finance, 17, 22-27. doi:10.1016/j.jbef.2017.12.004

Paulus, C. (2009). Der Saarbrücker Persönlichkeitsfragebogen SPF (IRI) zur Messung von Empathie: Psychometrische Evaluation der deutschen Version des Interpersonal Reactivity Index. Saarbrücken: Universität des Saarlandes.

Peer, E., Brandimarte, L., Samat, S., \& Acquisti, A. (2017). Beyond the Turk: Alternative platforms for crowdsourcing behavioral research. Journal of Experimental Social Psychology, 70, 153-163. doi:10.1016/j.jesp.2017.01.006

Poisnel, G., Arenaza-Urquijo, E., Collette, F., Klimecki, O. M., Marchant, N. L., Wirth, M., et al. (2018). The Age-Well randomized controlled trial of the Medit-Ageing European project: Effect of meditation or foreign language training on brain and mental health in older adults. Alzheimer's \& Dementia: Translational Research \& Clinical Interventions, 4, 714-723. doi:10.1016/j.trci.2018.10.011

Pommier, E. (2010). The compassion scale. In K. D. Neff (Ed.): ProQuest Dissertations Publishing.

Pommier, E., Neff, K. D., \& Tóth-Király, I. (2020). The Development and Validation of the Compassion Scale. Assessment, 27(1), 21-39. doi:10.1177/1073191119874108

Post, S. G., Underwood, L. G., Schloss, J. P., \& Hurlbut, W. B. (2002). Altruism and altruistic love: Science, philosophy, and religion in dialogue. Oxford University Press.

Rodrigues, J., Ulrich, N., Mussel, P., Carlo, G., \& Hewig, J. (2017). Measuring prosocial tendencies in Germany: sources of validity and reliablity of the revised prosocial tendency measure. Frontiers in psychology, 8, 2119. doi:10.3389/fpsyg.2017.02119 
Ricard, M. (2015). Altruism: The power of compassion to change yourself and the world: Hachette UK.

Schlosser M., Jones R., Demnitz-King H., Marchant N. L. (2020). Meditation experience is associated with lower levels of repetitive negative thinking: The key role of self-compassion. Current Psychology. In press.

Seppälä, E. M., Simon-Thomas, E., Brown, S. L., Worline, M. C., Cameron, C. D., \& Doty, J. R. (2017). The Oxford Handbook of Compassion Science (1 ed.): Oxford University Press.

Sprecher, S., \& Fehr, B. (2005). Compassionate love for close others and humanity. Journal of Social and Personal Relationships, 22(5), 629-651. doi:10.1177/0265407505056439

Strauss, C., Lever Taylor, B., Gu, J., Kuyken, W., Baer, R., Jones, F., \& Cavanagh, K. (2016). What is compassion and how can we measure it? A review of definitions and measures. Clinical Psychology Review, 47, 15-27. doi:10.1016/j.cpr.2016.05.004

Terwee, C. B., Bot, S. D. M., de Boer, M. R., van Der Windt, D. A. W. M., Knol, D. L., Dekker, J., et al. (2007). Quality criteria were proposed for measurement properties of health status questionnaires. Journal of Clinical Epidemiology, 60(1), 34-42.

doi:10.1016/j.jclinepi.2006.03.012

Underwood, L. G. (2002). The human experience of compassionate love: Conceptual mapping and data from selected studies. In S. G. Post, L. G. Underwood, J. Schloss, \& W. B. Hurlbut (Eds.), Altruism and altruistic love (pp. 72-88). Oxford: Oxford University Press.

Van Dam, N. T., van Vugt, M. K., Vago, D. R., Schmalzl, L., Saron, C. D., Olendzki, A., et al. (2018). Mind the Hype: A Critical Evaluation and Prescriptive Agenda for Research on Mindfulness and Meditation. Perspectives on Psychological Science, 13(1), 36-61. doi:10.1177/174569161770958 
Table 1:

Fit indices for one-factor confirmatory factor analyses of the English and German CLS and COS-7.

\begin{tabular}{llllll}
\hline Model & CFI & TLI & RMSEA $(90 \% \mathrm{Cl})$ & SRMR & Chi-square $(d f)$ \\
\hline CLS $^{\mathrm{a}}$ & 0.849 & 0.832 & $0.104(0.099-0.109)$ & $\mathbf{0 . 0 5 7}$ & $1215.13(189)$ \\
German CLS $^{\mathrm{b}}$ & 0.858 & 0.843 & $0.099(0.092-0.106)$ & $\mathbf{0 . 0 5 9}$ & $803.71(189)$ \\
COS-7 $^{\mathrm{a}}$ & $\mathbf{0 . 9 7 4}$ & $\mathbf{0 . 9 6 1}$ & $\mathbf{0 . 0 7 9}(0.058-0.101)$ & $\mathbf{0 . 0 2 8}$ & $57.67(14)$ \\
German COS-7 $^{\mathrm{b}}$ & $\mathbf{0 . 9 8 9}$ & $\mathbf{0 . 9 8 4}$ & $\mathbf{0 . 0 5 2}(0.019-0.082)$ & $\mathbf{0 . 0 2 3}$ & $\mathbf{2 6 . 5 9 ( 1 4 )}$ \\
\hline
\end{tabular}

Note. CLS = Compassionate Love Scale; COS-7 = 7-item Compassion for Others Scale; Cl = confidence interval; $d f=$ degrees of freedom; CFI = comparative fit index; TLI = Tucker-Lewis Index; RMSEA = root mean square error of approximation; SRMR = standardised root mean square residual. Bold indices indicate acceptable fit (RMSEA < 0.08 ) and excellent fit (CFI > 0.95; TLI > 0.95; SRMR < 0.8).

${ }^{\mathrm{a}} \mathrm{N}=501$

${ }^{\mathrm{b}} N=332$ 


\section{Table 2:}

CLS items and Reasons for Exclusion in the English COS-7 if applicable.

Original CLS item $^{\mathrm{a}}$ Reasons for exclusion

2.

3.

4.

5.

6.

7.

8.

9.

10.

11.

12.

13.

14.

15.

16.

17.

18.

19.

20.

21. Note. CLS = Compassionate Love Scale; COS-7 Interpersonal Reactivity Index.

${ }^{a}$ Bold items have been judged by experts to have adequate face validity.

Not clearly related to suffering
Includes the term "compassion"

Not clearly related to suffering only

Includes the term "compassionate"

Ambiguous (Gu et al. 2019; Strauss et al. 2016)

Includes the term "compassion"

Ambiguous (Gu et al. 2019; Strauss et al. 2016)

Ambiguous (Gu et al. 2019; Strauss et al. 2016)

Not clearly related to suffering

Not clearly related to suffering

Overlap with IRI (perspective taking, item 25): "When I'm upset at someone, I usually try to put myself in his shoes."

Not clearly related to suffering

Ambiguous (Gu et al. 2019; Strauss et al. 2016)

Not clearly related to suffering 
Table 3:

Distribution of item responses, reliability and item-test correlations; and factor loadings and model fit for the English COS-7 ( $N$ = 501).

\begin{tabular}{|c|c|c|c|c|c|}
\hline \multicolumn{6}{|c|}{ COS-7 } \\
\hline COS-7 item (Original CLS item) & Mean (SD) & Factor loading $^{a}$ & Commonality $^{b}$ & $\begin{array}{l}\text { Item-test } \\
\text { correlation }\end{array}$ & $\begin{array}{l}\text { Alpha if item } \\
\text { deleted }\end{array}$ \\
\hline 1. (1.) & $4.15(1.60)$ & 0.62 & 0.4 & 0.71 & 0.88 \\
\hline 2. (2.) & $4.39(1.58)$ & 0.65 & 0.4 & 0.73 & 0.88 \\
\hline 3. (5.) & $4.24(1.48)$ & 0.62 & 0.4 & 0.70 & 0.88 \\
\hline 4. (8.) & $3.93(1.62)$ & 0.71 & 0.5 & 0.77 & 0.87 \\
\hline 5. (10.) & $4.28(1.60)$ & 0.75 & 0.6 & 0.79 & 0.86 \\
\hline 6. (12.) & $4.39(1.50)$ & 0.85 & 0.7 & 0.84 & 0.86 \\
\hline 7. (15.) & $3.99(1.55)$ & 0.86 & 0.7 & 0.85 & 0.86 \\
\hline
\end{tabular}

Note. COS-7 = 7-item Compassion for Others Scale; CLS = Compassionate Love Scale; SD = standard deviation.

${ }^{a}$ Factor loadings are derived from confirmatory factor analyses of a one-factor solution.

${ }^{\mathrm{b}}$ Commonality is the proportion of the variance of an item accounted for by the factor. 
Table 4:

Correlations of the English COS-7 and CLS ( $N=501)$.

\begin{tabular}{|c|c|c|c|c|}
\hline & \multicolumn{2}{|c|}{ COS-7 } & \multicolumn{2}{|c|}{ CLS } \\
\hline & Correlation & $95 \% \mathrm{Cl}$ & Correlation & $95 \% \mathrm{Cl}$ \\
\hline Prosocialness $^{a}$ & $0.73^{* *}$ & 0.67 to 0.77 & $0.77^{* *}$ & 0.73 to 0.81 \\
\hline $\begin{array}{l}\text { Social value orientation }{ }^{b} \\
\text { Interpersonal reactivity } \\
\text { index }\end{array}$ & $0.26^{* *}$ & 0.16 to 0.35 & $0.30^{* *}$ & 0.21 to 0.39 \\
\hline Empathic concern & $0.65^{* *}$ & 0.59 to 0.71 & $0.68^{* *}$ & 0.62 to 0.73 \\
\hline Perspective taking & $0.38^{* *}$ & 0.29 to 0.46 & $0.48^{* *}$ & 0.40 to 0.56 \\
\hline Fantasy & 0.20 ** & 0.11 to 0.30 & $0.23^{* *}$ & 0.13 to 0.32 \\
\hline Personal distress & $0.14^{*}$ & 0.04 to 0.23 & $0.12^{*}$ & 0.03 to 0.22 \\
\hline CLS & $0.96^{* *}$ & 0.95 to 0.97 & - & - \\
\hline
\end{tabular}

Note. COS-7 = 7-item Compassion for Others Scale; CLS = Compassionate Love Scale;

$\mathrm{Cl}=$ confidence interval.

${ }^{a} n=382$

${ }^{\mathrm{b}} n=366$

${ }^{c} n=384$

${ }^{*} p<0.05$

${ }^{* *} p<0.001$ 
Table 5:

Distribution of item responses, reliability and item-test correlations; and factor loadings and model fit for the German $\mathrm{COS}-7$ ( $N=$ 332).

\begin{tabular}{|c|c|c|c|c|c|}
\hline \multicolumn{6}{|c|}{ German COS-7 } \\
\hline Item & Mean $(S D)$ & $\begin{array}{l}\text { Factor } \\
\text { loading }\end{array}$ & Commonality $^{b}$ & $\begin{array}{l}\text { Item-test } \\
\text { correlation }\end{array}$ & $\begin{array}{l}\text { Alpha if item } \\
\text { deleted }\end{array}$ \\
\hline $\begin{array}{l}\text { 1. Wenn ich sehe, dass Menschen, die ich nicht kenne, traurig } \\
\text { sind, fühle ich das Bedürfnis, mich ihnen zuzuwenden. }\end{array}$ & $4.40(1.66)$ & 0.76 & 0.6 & 0.80 & 0.87 \\
\hline $\begin{array}{l}\text { 2. Ich verbringe viel Zeit damit, mich mit dem Wohlergehen der } \\
\text { Menschheit zu befassen. }\end{array}$ & $4.10(1.63)$ & 0.70 & 0.5 & 0.77 & 0.88 \\
\hline $\begin{array}{l}\text { 3. Wenn ich einer fremden Person begegne, die Hilfe braucht, } \\
\text { würde ich fast alles tun, was ich kann, um ihr zu helfen. }\end{array}$ & $4.23(1.47)$ & 0.65 & 0.4 & 0.72 & 0.88 \\
\hline $\begin{array}{l}\text { 4. Wenn sich die Gelegenheit bietet, bin ich dazu bereit, auf } \\
\text { etwas zu verzichten, damit Personen von anderswo, die weniger } \\
\text { Glück haben, ihre Ziele erreichen können. }\end{array}$ & $4.35(1.51)$ & 0.59 & 0.3 & 0.68 & 0.89 \\
\hline $\begin{array}{l}\text { 5. Eine der Tätigkeiten, die mich am meisten in meinem Leben } \\
\text { erfüllt, ist es, anderen in der Welt zu helfen, wenn sie Hilfe } \\
\text { brauchen. }\end{array}$ & $3.82(1.62)$ & 0.75 & 0.6 & 0.79 & 0.87 \\
\hline $\begin{array}{l}\text { 6. Ich habe oft warmherzige Gefühle gegenüber anderen } \\
\text { (Fremden), wenn es scheint, dass diese Menschen ein Bedürfnis } \\
\text { haben. }\end{array}$ & $4.15(1.54)$ & 0.85 & 0.7 & 0.85 & 0.86 \\
\hline $\begin{array}{l}\text { 7. Wenn eine fremde Person in Schwierigkeiten ist, fühle ich in } \\
\text { der Regel ein starkes Mitgefühl und Fürsorge. }\end{array}$ & $4.31(1.47)$ & 0.84 & 0.7 & 0.84 & 0.86 \\
\hline
\end{tabular}
der Regel ein starkes Mitgefühl und Fürsorge.

Note. COS-7 = 7-item Compassion for Others Scale; SD = standard deviation.

${ }^{a}$ Factor loadings are derived from confirmatory factor analyses of a one-factor solution.

${ }^{b}$ Commonality is the proportion of the variance of an item accounted for by the factor. 
Table 6:

Correlations of the German COS-7 and CLS ( $N=332)$.

\begin{tabular}{|c|c|c|c|c|}
\hline & \multicolumn{2}{|c|}{ German COS-7 } & \multicolumn{2}{|c|}{ German CLS } \\
\hline & Correlation & $95 \% \mathrm{Cl}$ & Correlation & $95 \% \mathrm{Cl}$ \\
\hline \multicolumn{5}{|l|}{ Prosocial tendencies } \\
\hline Altruism & 0.07 & -0.04 to 0.17 & 0.10 & -0.01 to 0.20 \\
\hline Anonymous & $0.41^{* *}$ & 0.32 to 0.50 & $0.41^{* *}$ & 0.32 to 0.50 \\
\hline Public & 0.10 & -0.01 to 0.20 & 0.08 & -0.03 to 0.18 \\
\hline Emotional & $0.62_{* * *}^{* *}$ & 0.55 to 0.68 & $0.62^{* *}$ & 0.54 to 0.68 \\
\hline Dire & $0.53^{* *}$ & 0.45 to 0.60 & $0.54^{* *}$ & 0.46 to 0.61 \\
\hline Compliant & $0.46^{* *}$ & 0.37 to 0.54 & $0.47^{\star *}$ & 0.38 to 0.55 \\
\hline $\begin{array}{l}\text { Social value orientation }{ }^{a} \\
\text { Interpersonal reactivity index }\end{array}$ & $0.39^{* *}$ & 0.30 to 0.48 & $0.40^{* *}$ & 0.30 to 0.48 \\
\hline Empathic concern & $0.73^{* *}$ & 0.68 to 0.78 & $0.75^{\star *}$ & 0.70 to 0.79 \\
\hline Perspective taking & $0.46^{* *}$ & 0.37 to 0.54 & $0.53^{* *}$ & 0.45 to 0.60 \\
\hline Fantasy & $0.40^{* *}$ & 0.31 to 0.49 & $0.42^{* *}$ & 0.33 to 0.51 \\
\hline Personal distress & $0.17^{*}$ & 0.06 to 0.27 & $0.17^{*}$ & 0.07 to 0.28 \\
\hline German CLS & $0.96^{* *}$ & 0.95 to 0.96 & - & - \\
\hline \multicolumn{5}{|c|}{$\begin{array}{l}\text { Note. COS-7 = 7-item Compassion for Others Scale; CLS = Compassionate Love Scale; } \\
\mathrm{Cl}=\text { confidence interval. } \\
{ }^{a} n=330 \\
{ }^{*} p<0.01\end{array}$} \\
\hline
\end{tabular}




\section{Table S1:}

German translation of the Compassionate Love Scale.

1. Wenn ich sehe, dass Menschen, die ich nicht kenne, traurig sind, fühle ich das Bedürfnis, mich innen zuzuwenden.

2. Ich verbringe viel Zeit damit, mich mit dem Wohlergehen der Menschheit zu befassen.

3. Wenn ich höre, dass jemand (eine fremde Person) gerade eine schwierige Zeit durchlebt, empfinde ich großes Mitgefühl für sie/ihn.

4. Es fällt mir leicht, den Schmerz (und die Freude) anderer zu empfinden, selbst wenn ich die anderen nicht kenne.

5. Wenn ich einer fremden Person begegne, die Hilfe braucht, würde ich fast alles tun, was ich kann, um ihr zu helfen.

6. Ich empfinde in hohem Maße mitfühlende Liebe für Menschen aus aller Welt.

7. Ich würde eher selbst leiden, als eine andere fremde Person leiden zu sehen.

8. Wenn sich die Gelegenheit bietet, bin ich dazu bereit, auf etwas zu verzichten, damit Personen von anderswo, die weniger Glück haben, ihre Ziele erreichen können.

9. Ich neige dazu, Mitgefühl für andere Menschen zu empfinden, auch wenn ich sie nicht kenne.

10. Eine der Tätigkeiten, die mich am meisten in meinem Leben erfüllt, ist es, anderen in der Welt zu helfen, wenn sie Hilfe brauchen.

11. Ich würde mich eher an Vorhaben beteiligen, die anderen zu Gute kommen, auch wenn es sich um Fremde handelt, als an Vorhaben, die mir selbst helfen.

12. Ich habe oft warmherzige Gefühle gegenüber anderen (Fremden), wenn es scheint, dass diese Menschen ein Bedürfnis haben.

13. Ich empfinde eine selbstlose Anteilnahme für den Großteil der Menschheit.

14. Ich akzeptiere andere, die ich nicht kenne, auch wenn sie Dinge tun, die ich für falsch halte.

15. Wenn eine fremde Person in Schwierigkeiten ist, fühle ich in der Regel ein starkes Mitgefühl und Fürsorge.

16. Ich versuche eher, mir fremde Personen zu verstehen, als über sie zu urteilen.

17. Ich versuche mich in die Lage einer fremden Person zu versetzen, wenn diese Person in Schwierigkeiten ist.

18. Ich fühle mich glücklich, wenn ich sehe, dass andere (Fremde) glücklich sind.

19. Personen, die mir in meinem beruflichen oder öffentlichen Leben begegnen, können davon ausgehen, dass ich für sie da sein werde, wenn sie mich brauchen.

20. Ich möchte Zeit mit Menschen verbringen, die ich nicht gut kenne, damit ich Möglichkeiten finden kann, die ihnen helfen, ihr Leben zu bereichern.

21. Es liegt mir sehr viel daran, freundlich und gut zu meinem Mitmenschen zu sein. 